\title{
DFT Study of Molecular and Electronic Structure of Y, La and Lu Complexes with Porphyrazine and Tetrakis(1,2,5-thiadiazole)porphyrazine
}

\author{
Yuriy A. Zhabanov *, Igor V. Ryzhov, Ilya A. Kuzmin, Alexey V. Eroshin (i) and Pavel A. Stuzhin
}

Citation: Zhabanov, Y.A.; Ryzhov,

I.V.; Kuzmin, I.A.; Eroshin, A.V.; Stuzhin, P.A. DFT Study of Molecular and Electronic Structure of Y, La and Lu Complexes with Porphyrazine and Tetrakis(1,2,5-thiadiazole)porphyrazine. Molecules 2021, 26, 113. https:/ / doi. org $/ 10.3390 /$ molecules 26010113

Academic Editors: Mikhail F. Butman Oscar I. Koifman, Giuseppe Arena and Benedito José Costa Cabral Received: 27 November 2020 Accepted: 25 December 2020 Published: 29 December 2020

Publisher's Note: MDPI stays neutral with regard to jurisdictional clai$\mathrm{ms}$ in published maps and institutional affiliations.

Copyright: $@ 2020$ by the authors. Licensee MDPI, Basel, Switzerland. This article is an open access article distributed under the terms and conditions of the Creative Commons Attribution (CC BY) license (https:// creativecommons.org/licenses/by/ $4.0 /)$.
Research Institute of Chemistry of Macroheterocyclic Compounds, Ivanovo State University of Chemistry and Technology, Sheremetievskiy av. 7, 153000 Ivanovo, Russia; ryzhoff.ihor@yandex.ru (I.V.R.); wonderful_37@list.ru (I.A.K.); alexey.yeroshin@gmail.com (A.V.E.); stuzhin@isuct.ru (P.A.S.)

* Correspondence: zhabanov@isuct.ru; Tel.: +7-4932-35-98-74

Abstract: Electronic and geometric structures of Y, La and Lu complexes with porphyrazine (Pz) and tetrakis(1,2,5-thiadiazole)porphyrazine (TTDPz) were investigated by density functional theory (DFT) calculations and compared. The nature of the bonds between metal atoms and nitrogen atoms has been described using the analysis of the electron density distribution in the frame of Bader's quantum theory of atoms in molecule (QTAIM). Simulation and interpretation of electronic spectra were performed with use of time-dependent density functional theory (TDDFT) calculations. Description of calculated IR spectra was carried out based on the analysis of the distribution of the potential energy of normal vibrations by natural vibrational coordinates.

Keywords: porphyrazine; 1,2,5-thiadiazole annulated; DFT study; molecular and electronic structure

\section{Introduction}

Macroheterocycles such as porphyrines, phthalocyanines and their analogues have found a number of applications [1-4]. The possibility of modification of peripheral substituents [5] or atoms in a central ring allows fine-tuning or modulation of their properties $[5,6]$ such as stability, rigidity, extended conjugated $\pi$-electron cloud, conductivity, light absorption capability, long-lived fluorescence, possibility to host uncoupled electrons on the central metal ion or in the aromatic cloud, and so on [7].

Substitution of benzene rings in phthalocyanines by aromatic heterocycles, e.g., by pyrazine [8,9] or 1,2,5-chalcogenadiazole [10] have a strong impact of the electronic properties of the central porphyrazine $(\mathrm{Pz})$ core which is common for these systems.

The presence of a five-membered heterocycle containing nitrogen and sulfur atoms on the periphery of tetrakis(1,2,5-thiadiazole)porphyrazine (TTDPz) considerably modulates the physico-chemical properties of the macrocycle and its ability for intermolecular interaction as compared to phthalocyanines [10]. Unlike phthalocyanines, or their pyrazine-fused analogues, TTDPz have no $\mathrm{H}$ atoms on the periphery and their molecular packing during crystal growth is determined by specific N . . S interactions [11]. This is quite important for application of these phthalocyanine-type molecules as building blocks for novel functional materials in various fields [12].

Lanthanide complexes of phthalocyanines due to their rich structural diversity and peculiar spectral and electrochemical properties [13] are especially interesting as components of different devices [14]. Among the metal complexes of TTDPz, macrocycle complexes of p- and d-metals are known [MTTDPz]: $\mathrm{M}=\mathrm{Li}$ [15], $\mathrm{Mg}$ [16], Ca [17], $\mathrm{AlCl}$, $\mathrm{GaCl}$, InOAc [18], Zn, Cu, Ni, Co, Fe, Mn [11,16,19]. Recently we have also obtained first representatives of the rare earth metal complexes [(acac)YTTDPz], [(acac)LuTTDPz] [20]. Among lanthanide complexes of unsubstituted porphyrazine [(acac)MPz] complexes with dysprosium, neodium and europium have been reported [21,22]. 
The optical and coordination properties of phthalocyanine-type complexes crucially depend on the electronic structure of the metal and macrocycle and can often be predicted by quantum-chemical calculations. Such investigations in the case of transition metal complexes $\mathrm{s}$ are often nontrivial due to the necessity to account for the multireference character of the wavefunction [23]. However the information about the ground-state properties can be readily obtained for closed-shell species. Density functional theory (DFT) provides a straightforward way to obtain quantitative and qualitative information about structural, electronic and spectral features. It is quite important to investigate the influence of a transition metal and a macrocyclic ligand on the properties of the porphyrine-type complexes, particularly, the peculiarities of chemical bonding and spectral properties. Comparison in the series of atoms of $\mathrm{d}^{1}$ metals with a different radius ( $\mathrm{Y}$, $\mathrm{La}$ and $\mathrm{Lu}$ ) allows the taking into account of only the size of atoms. The change of the periphery of the porphyrazine macrocycle (Pz) by fusion of electron-deficient 1,2,5-thiadiazole rings (TTDPz) allows the determination of the influence of the ligand on the coordination properties of central atoms.

Earlier in our laboratory, the $\mathrm{Ca}, \mathrm{Fe}$, Co and $\mathrm{Zn}$ complexes with porphyrazines and tetrathiadiazoporphyrazines ligands were investigated by quantum-chemical calculations $[17,23]$. Preliminary quantum-chemical calculations and interpretation of vibrational spectra were also carried out for complexes of tetra(1,2,5-thiadiazolo)porphyrazine with rare earth elements $\mathrm{Y}$ and $\mathrm{Lu}$ [20]. The main objective of the present study is to identify the influence of the molecular and electronic structures on the properties of macrocyclic complexes. It is quite important to compare the TTDPz complexes with the corresponding complexes of nonsubstituted porphyrazine in order to reveal the impact of annulation of the 1,2,5-thiadiazole rings. The nature of the chemical bonding between metal atoms and nitrogen atoms has been described using the analysis of the electron density distribution in the framework of Bader's quantum theory of atoms in molecules (QTAIM) [24]. The lowest excited states were also calculated in order to explain the peculiarities and tendencies observed in the experimental electronic absorption spectra available for the $Y$ and Lu tetra(1,2,5-thiadiazolo)porphyrazine complexes [20]. In addition, the vibrational absorption spectra were analyzed and interpreted.

\section{Results and Discussion}

\subsection{Geometric Structure}

Equilibrium structures of the $\mathrm{Y}, \mathrm{La}$ and Lu macroheterocyclic complexes with porphyrazine $(\mathrm{MClPz})$ and tetra(1,2,5-thiadiazolo)porphyrazine (MClTTDPz) bearing chloride as an axial ligand, were found to possess $\mathrm{C}_{4 \mathrm{v}}$ symmetry with doming distortion (Figure 1). Force-field calculations yielded no imaginary frequencies, indicating that the optimized configurations correspond to the minima on the potential energy hypersurfaces. The calculated molecular parameters are listed in Table 1.

Analysis of the data in Table 1 shows that there is a significant difference (maximum is about $0.2 \AA$ ) in the internuclear distances $\mathrm{M}-\mathrm{Cl}$ and $\mathrm{M}-\mathrm{N}_{\mathrm{p}}$ in the series of studied complexes, as well as in the parameters $\mathrm{M}-\mathrm{X} 1$ and $\mathrm{X} 1-\mathrm{X} 2$ which characterize the distortion of the macrocyclic ligand. The change in the size of the coordination cavity $\left(\mathrm{N}_{\mathrm{p}} \ldots \mathrm{N}_{\mathrm{p}}\right)_{\text {opp }}$ of the ligand is also quite large in MCITTDPz over against MClPz. Additionally there is an increase of M-Cl, M- $\mathrm{N}_{\mathrm{p}},\left(\mathrm{N}_{\mathrm{p}} \ldots \mathrm{N}_{\mathrm{p}}\right)_{\text {opp }}$ and $\left(\mathrm{N}_{\mathrm{p}} \ldots \mathrm{N}_{\mathrm{p}}\right)_{\text {adj }}$ distances in the LuClPz-YClPz$\mathrm{LaClPz}$ series, corresponding to the increase in the ionic radius of metals [25]. A similar situation is observed for MCITTDPz. It should be noted that changes in the analogous parameters of MPz and MTTDPz complexes with a number of transition, alkali and alkali earth metals $[15,17,23]$ are comparable to changes in the parameters of the complexes considered in this work. Obviously, such differences are due to the nature of the metals introduced into the macrocycle cavity. However, the nature of the metal has practically no effect on the structure of the periphery of the ligand, since the internuclear distances $\mathrm{N}_{\mathrm{p}}-\mathrm{C}_{\alpha}, \mathrm{C}_{\alpha}-\mathrm{N}_{\mathrm{m}}, \mathrm{C}_{\alpha}-\mathrm{C}_{\beta}, \mathrm{C}_{\beta}-\mathrm{C}_{\beta}, \mathrm{C}_{\beta}-\mathrm{H}$ (for MClPz), $\mathrm{C}_{\beta}-\mathrm{N}_{\mathrm{t}}$, and $\mathrm{N}_{\mathrm{t}}-\mathrm{S}$ (for MClTTDPz) in the macrocyclic fragment change by no more than $0.002 \AA$, and the bond angles $\mathrm{N}_{\mathrm{p}} \mathrm{C}_{\alpha} \mathrm{N}_{\mathrm{m}}$, 
$\mathrm{C}_{\alpha} \mathrm{N}_{\mathrm{m}} \mathrm{C}_{\alpha}, \mathrm{C}_{\alpha} \mathrm{N}_{\mathrm{p}} \mathrm{C}_{\alpha}$ and $\mathrm{N}_{\mathrm{t}} \mathrm{SN}_{\mathrm{t}}$ (for MClTTDPz) change by no more than 0.5 degrees. Thus, we can conclude that the change in metal affects only the size of the macrocyclic cavity. It should also be noted that the introduction of thiadiazole as a substituent changes the bond lengths of pyrrole moieties by no more than $0.07 \AA$, and the values of bond angles change by no more than 4 degrees.

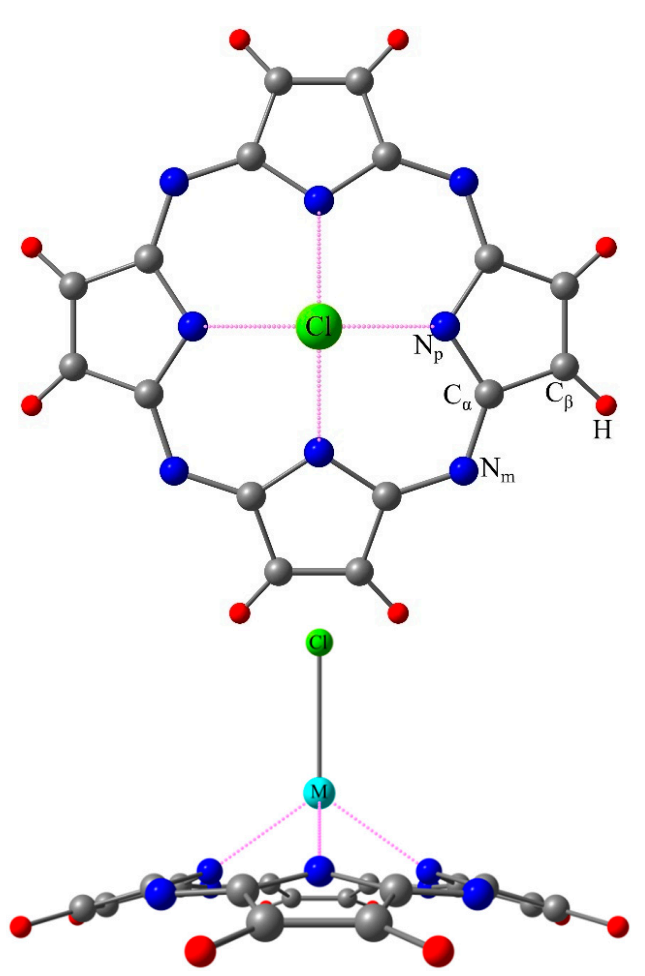

(a)

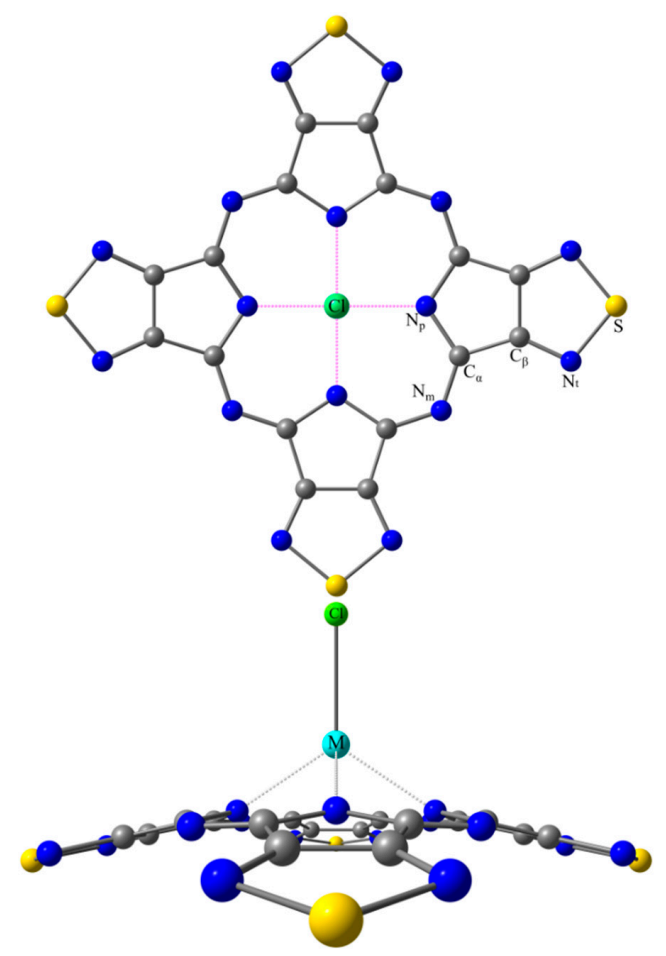

(b)

Figure 1. Molecular models of porphyrazine (MClPz) (a) and tetra(1,2,5-thiadiazolo)porphyrazine (MClTTDPz) (b) complexes with atom labeling $(\mathrm{M}=\mathrm{Y}, \mathrm{La}, \mathrm{Lu})$.

Table 1. Internuclear distances $\left(\mathrm{r}_{\mathrm{e}}\right.$, in $\AA$ ) and valence angles $\left(\angle\right.$, in deg.) of the equilibrium $\mathrm{C}_{4 \mathrm{v}}$ structures by B3LYP/pcseg-2 calculations.

\begin{tabular}{|c|c|c|c|c|c|c|}
\hline & $\mathrm{LaClPz}$ & LaClTTDPz & $\mathrm{LuClPz}$ & LuCITTDPz & $\mathrm{YClPz}$ & YCITTDPz \\
\hline $\mathrm{M}-\mathrm{Cl}$ & 2.711 & 2.680 & 2.493 & 2.468 & 2.523 & 2.497 \\
\hline$M-N_{p}$ & 2.462 & 2.486 & 2.260 & 2.284 & 2.291 & 2.313 \\
\hline $\mathrm{N}_{\mathrm{p}}-\mathrm{C}_{\alpha}$ & 1.369 & 1.377 & 1.370 & 1.379 & 1.370 & 1.379 \\
\hline $\mathrm{C}_{\alpha}-\mathrm{N}_{\mathrm{m}}$ & 1.330 & 1.321 & 1.329 & 1.319 & 1.329 & 1.319 \\
\hline $\mathrm{C}_{\alpha}-\mathrm{C}_{\beta}$ & 1.456 & 1.460 & 1.454 & 1.458 & 1.454 & 1.458 \\
\hline$C_{\beta}-C_{\beta}$ & 1.355 & 1.423 & 1.355 & 1.422 & 1.355 & 1.422 \\
\hline $\mathrm{C}_{\beta}-\mathrm{H}$ & 1.077 & & 1.077 & & 1.077 & \\
\hline$C_{\beta}-N_{t}$ & & 1.316 & & 1.317 & & 1.317 \\
\hline $\mathrm{N}_{\mathrm{t}}-\mathrm{S}$ & & 1.644 & & 1.643 & & 1.643 \\
\hline$\left(N_{p} \ldots N_{p}\right)_{o p p}$ & 4.023 & 4.139 & 3.979 & 4.096 & 3.987 & 4.101 \\
\hline$\left(\mathrm{N}_{\mathrm{p}} \ldots \mathrm{N}_{\mathrm{p}}\right)_{\mathrm{adj}}$ & 2.844 & 2.927 & 2.813 & 2.897 & 2.819 & 2.900 \\
\hline$\angle\left(\mathrm{N}_{\mathrm{p}} \mathrm{MCl}\right)$ & 125.2 & 123.6 & 118.3 & 116.3 & 119.5 & 117.6 \\
\hline$\angle\left(\mathrm{MN}_{\mathrm{p}} \mathrm{C}_{\alpha}\right)$ & 124.7 & 122.4 & 125.1 & 123.1 & 125.2 & 122.9 \\
\hline$\angle\left(\mathrm{N}_{\mathrm{p}} \mathrm{C}_{\alpha} \mathrm{N}_{\mathrm{m}}\right)$ & 127.6 & 128.1 & 127.3 & 127.9 & 127.4 & 128.0 \\
\hline$\angle\left(\mathrm{C}_{\alpha} \mathrm{N}_{\mathrm{m}} \mathrm{C}_{\alpha}\right)$ & 125.0 & 127.1 & 124.5 & 126.6 & 124.6 & 126.7 \\
\hline$\angle\left(\mathrm{C}_{\alpha} \mathrm{N}_{\mathrm{p}} \mathrm{C}_{\alpha}\right)$ & 107.5 & 111.6 & 107.6 & 111.5 & 107.6 & 111.6 \\
\hline$\angle\left(\mathrm{N}_{\mathrm{t}} \mathrm{SN}_{\mathrm{t}}\right)$ & & 100.3 & & 100.4 & & 100.4 \\
\hline $\mathrm{M}-\mathrm{X} 1^{1}$ & 1.419 & 1.377 & 1.072 & 1.011 & 1.129 & 1.071 \\
\hline$X 1-X 2^{2}$ & & 1.028 & & 0.775 & & 0.767 \\
\hline
\end{tabular}

\footnotetext{
${ }^{1} \mathrm{X} 1$ is dummy atom located in center between $\mathrm{N}_{\mathrm{p}}$ atoms. ${ }^{2} \mathrm{X} 2$ is dummy atom located in center between $\mathrm{S}$ atoms.
} 
The value of lanthanide contraction $\Delta \mathrm{r}_{\mathrm{Ln}}$, which may be estimated as a difference between $r\left(L a-N_{p}\right)$ and $r\left(L u-N_{p}\right)$ distance values, is $0.202 \AA$ for both MClPz and MClTTDPz. It should be noted that the obtained value of $\Delta \mathrm{r}_{\mathrm{Ln}}$ is close to similar theoretical value in the series of compounds with tridentate ligand (0.208 $\AA$ ) [26], experimental values in the series of $\mathrm{ML}_{3}$ with monovalent ligands, such as the series of trichlorides $(0.186(8) \AA)$, tribromides $(0.185(8) \AA$ ) and triiodides $(0.193(8) \AA)$ [27-31], as well as in the series of compounds with bidentate ligands, for example, in the series of tris-dipivaloylmethanates $(0.186(6) \AA)[32,33]$. The similarity of $\Delta \mathrm{r}_{\mathrm{Ln}}$ values in lanthanide compounds with three ligands and in complexes considered in the present study indicates that, with no regard of the size of the central atom in the lanthanide series, the geometric structure of the coordination cavity is adjusted to the size of the central atom with the formation of coordination bonds.

\subsection{Electron Density Distribution and Chemical Bonding in MClPz and MClTTDPz}

Selected net atomic charges and topological parameters of the electron density in bond critical points (BCP) are listed in Table 2. According to the Table 2 the incorporation of thiadiazole rings does not lead to a significant change in the charge of the metal and the ligands (the charge of the macroheterocyclic ligand is calculated as the sum of the net atomic charges on the ligand atoms). The presence of electron-withdrawing nitrogen atoms in the thiadiazole rings induces a shift of electron density from the central cavity and leads to a charge transfer in the row $\mathrm{N}_{t} \leftarrow \mathrm{C}_{\beta} \leftarrow \mathrm{C}_{\alpha}$. It should be noted that the charges on the atoms of the internal macrocycle $\left(\mathrm{C}_{\alpha}, \mathrm{N}_{\mathrm{p}}, \mathrm{N}_{\mathrm{m}}\right)$ also do not change significantly, but the charge on the carbon atom $C_{\beta}$ increases by 0.4 e (Table 2). Similar tendencies in the change of the charges were revealed in the complexes MPz and MTTDPz with transition metals $\mathrm{Ca}, \mathrm{Fe}, \mathrm{Co}$ and $\mathrm{Zn}[17,23]$. The charge on the metal atoms is about +2.2 e, which is comparable to the charge on the $\mathrm{Y}, \mathrm{La}$ and $\mathrm{Lu}$ atoms in the tridentate macroheterocyclic ligand [26]. In the studied complexes the charge of a ligand varies from -1.447 to $-1.362 \mathrm{e}$, and in complexes with transition metals from -1.580 to $-1.141 \mathrm{e}$. In addition, the charges on the atoms of the internal macrocycle $\left(C_{\alpha}, N_{p}, N_{m}\right)$ are close to each other in the case of all the complexes considered (the complexes studied in this work and the complexes with transition metals $[17,23])$. Based on the above-mentioned considerations, it can be concluded that the electron density distribution in the coordination cavity of metal complexes of porphyrazine and tetra(1,2,5-thiadiazole)porphyrazine metal does not change significantly regardless of metal nature and thiadiazole annelation.

Table 2. Selected parameters of MCIPz and MCITTDPz complexes from quantum theory of atoms in molecules (QTAIM) calculations.

\begin{tabular}{ccccccc}
\hline & YClPz & LaClPz & LuClPz & YClTTDPz & LaClTTDPz & LuClTTDPz \\
\hline$\nabla^{2} \rho\left(\mathrm{M}-\mathrm{N}_{\mathrm{p}}\right)$, a.u. & 0.205 & 0.160 & 0.235 & 0.193 & 0.152 & 0.221 \\
$\mathrm{q}\left(\mathrm{M} \mid \mathrm{N}_{\mathrm{p}}\right)$ & 0.348 & 0.356 & 0.340 & 0.354 & 0.362 & 0.347 \\
$\delta\left(\mathrm{M} \mid \mathrm{N}_{\mathrm{p}}\right)$ & 0.349 & 0.366 & 0.357 & 0.337 & 0.353 & 0.346 \\
$\mathrm{q}(\mathrm{M} \mid \mathrm{Cl})$ & 0.779 & 0.793 & 0.763 & 0.757 & 0.770 & 0.740 \\
$\delta(\mathrm{M} \mid \mathrm{Cl})$ & 0.536 & 0.564 & 0.552 & 0.574 & 0.606 & 0.588 \\
$\mathrm{q}(\mathrm{M})$ & +2.171 & +2.21 & +2.125 & +2.173 & +2.218 & +2.127 \\
$\mathrm{q}\left(\mathrm{N}_{\mathrm{p}}\right)$ & -1.191 & -1.179 & -1.187 & -1.164 & -1.153 & -1.16 \\
$\mathrm{q}\left(\mathrm{N}_{\mathrm{m}}\right)$ & -1.121 & -1.123 & -1.121 & -1.124 & -1.125 & -1.123 \\
$\mathrm{q}\left(\mathrm{C}_{\alpha}\right)$ & 0.928 & 0.920 & 0.929 & 0.963 & 0.958 & 0.963 \\
$\mathrm{q}\left(\mathrm{C}_{\beta}\right)$ & 0.017 & 0.014 & 0.017 & 0.526 & 0.525 & 0.526 \\
$\mathrm{q}($ ligand $)$ & -1.391 & -1.423 & -1.362 & -1.416 & -1.447 & -1.386 \\
\hline
\end{tabular}

1 The sum of the net atomic charges on the ligand atoms. 
The nature of a chemical bond can be determined by the value of the electron density, laplacian $\nabla^{2} \rho$. A positive value of the electron density laplacian $\nabla^{2} \rho$ indicates ionic interaction. However, the positive values of $\nabla^{2} \rho$ for $\mathrm{M}-\mathrm{Cl}$ bonds, as well as the corresponding delocalization indices $\delta(\mathrm{M} \mid \mathrm{Cl})$ representing the magnitudes of the electron exchange between the basins of the corresponding atoms, allow to argue that these bonds, along with an ionic component (Table 2), possess a significant covalent component (about 0.6). Moreover, it can be noted that the internuclear distances $\mathrm{r}(\mathrm{M}-\mathrm{Cl})$ decrease by $0.03 \AA$ and the delocalization indices increase by about 0.04 in the MCITTDPz complexes as compared to their $\mathrm{MClPz}$ analogues. Values of the parameters $\nabla^{2} \rho, \delta\left(\mathrm{M} \mid \mathrm{N}_{\mathrm{p}}\right)$ and $\mathrm{q}\left(\mathrm{M} \mid \mathrm{N}_{\mathrm{p}}\right)($ Table 2$)$ indicate mainly the ionic $\mathrm{M}-\mathrm{N}_{\mathrm{p}}$ bond with a noticeable covalent component (value of $\delta\left(\mathrm{M} \mid \mathrm{N}_{\mathrm{p}}\right)$ ) comparable to the corresponding value for the Pz and TTDPz complexes with $\mathrm{Ca}$ and $\mathrm{Zn}[17]$.

\subsection{Electronic Absorption Spectra}

The electronic absorption spectra of MClPz and MCITTDPz molecules simulated on the basis of time-dependent density functional theory (TDDFT) calculations are shown in Figure 2. The calculated electronic spectra of complexes MClPz and MCITTDPz (M=Y, La, $\mathrm{Lu})$ are quite similar. The main difference in the electronic absorption spectra in the $\mathrm{MClPz}$ series is the bathochromic shift of the $\mathrm{B}_{\mathrm{x}}\left(\lambda_{2}\right)$ band. In the case of MCITTDPz molecules, the difference in the electronic spectra appears in the change of positions and relative intensities of the $B_{x}\left(\lambda_{2}\right)$ and $B_{y}\left(\lambda_{3}\right)$ bands, as well as in the relatively small bathochromic shift of the Q-band $\left(\lambda_{1}\right)$. In general, the spectra can be described by the model of Gouterman [34-36], who suggested electronic absorption spectra of porphyrazine molecules, to possess four intense bands $B_{x}, B_{y}, Q_{x}$, and $Q_{y}$, and three bands $\left(B_{x}, B_{y}\right.$, and $\left.Q\right)$ in the case of their metal complexes. Interpretation of the electronic spectra was carried out on the basis of the results of TDDFT calculations. The calculated oscillator strengths (f) for the lowest excited states along with their composition (in terms of one-electron transitions) are given in Table 3 (full list of the most active transitions can be found in Supplementary Materials). Analysis of the data in Table 3 demonstrates that there are three excited electronic states of $\mathrm{MClPz}$ molecules characterized by a high oscillator strength. These transitions correspond to three intense bands $-\mathrm{B}_{\mathrm{x}}, \mathrm{B}_{\mathrm{y}}$, and $\mathrm{Q}$. The low-lying calculated excited state $1^{1} \mathrm{E}$ for $\mathrm{MClPz}$ complexes is formed predominantly by the electronic transitions from HOMO and HOMO1 to LUMO, which can be assigned to the Q-band. It should be noted that the compositions of the wave functions and the oscillator strengths corresponding to the electronic state $1^{1} \mathrm{E}$ are very close to each other for all $\mathrm{MClPz}(\mathrm{M}=\mathrm{Y}, \mathrm{La}, \mathrm{Lu})$ complexes. The excited state $4^{1} \mathrm{E}$ of $\mathrm{MClPz}$ is formed by the similar electronic transitions and corresponds to the $\mathrm{B}_{\mathrm{x}}$ band, which is shifted to larger wavelengths in the case of $\mathrm{LaClPz}$. Transitions in the higher excited states are predicted to have a highest oscillator strength and can be associated with the $\mathrm{B}_{\mathrm{y}}$ band. These excited states $\left(6^{1} \mathrm{E}\right.$ for $\mathrm{LaClPz}$ and $5^{1} \mathrm{E}$ for $\mathrm{YClPz}$ and $\mathrm{LuClPz}$ complexes) are composed mainly of the electronic transitions from $\mathrm{a}_{1}$ and $\mathrm{a}_{2}$ orbitals to the LUMO $e^{*}$. The changes of electronic spectra are more significant in complexes of the MCITTDPz (Figure 2, Table 3), where the $B_{x}$ and $B_{y}$ bands are different in wavelengths and relative intensities. Thus, it can be concluded that the incorporation of a substituent can enhance the effect of the metal on the spectral properties of the complexes. 


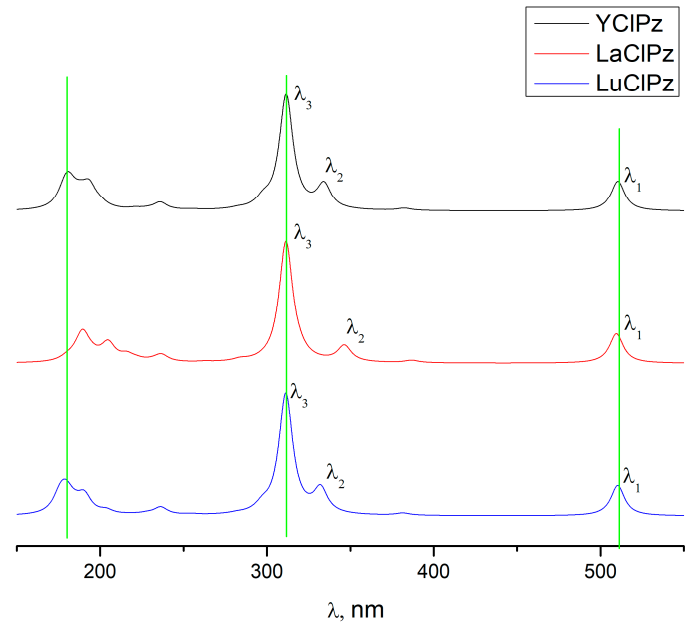

(a)

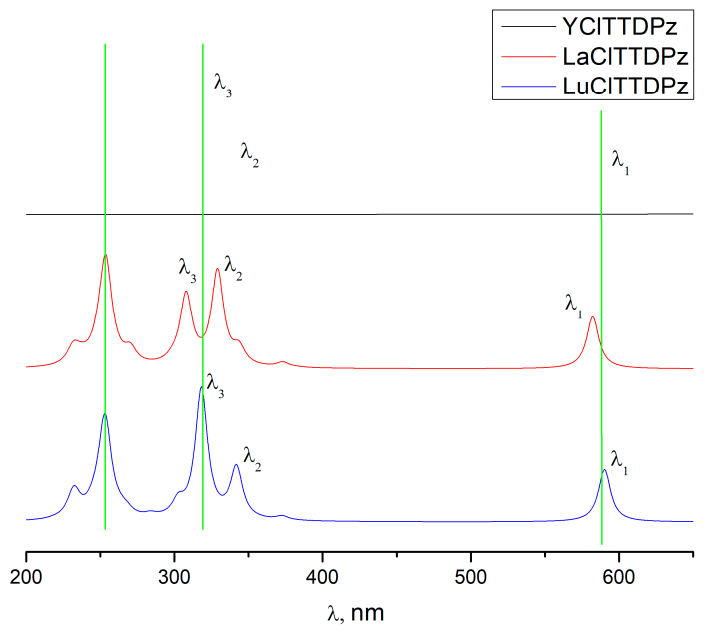

(b)

Figure 2. Calculated time-dependent density functional theory (TDDFT) electronic absorption spectra for $\mathrm{MCIPz}$ (a) and MCITTDPz (b) complexes.

Table 3. Calculated mposition of the lowest excited states and corresponding oscillator strengths for $\mathrm{MClPz}$ and MCITTDPz complexes.

\begin{tabular}{|c|c|c|c|c|}
\hline State & Composition (\%) & $\Lambda(\mathrm{nm})$ & f & \\
\hline \multicolumn{5}{|l|}{$\mathrm{YClPz}$} \\
\hline $1^{1} \mathrm{E}$ & $\begin{array}{c}2 a_{1} \rightarrow e^{*}(16) \\
a_{2} \rightarrow e^{*}(82) \\
1 a_{1} \rightarrow e^{*}(53)\end{array}$ & 510 & 0.15 & $\lambda_{1}$ \\
\hline $4^{1} \mathrm{E}$ & $\begin{aligned} 2 a_{1} & \rightarrow e^{*} \\
a_{2} & \rightarrow e^{*}\end{aligned}$ & 334 & 0.13 & $\lambda_{2}$ \\
\hline $5^{1} \mathrm{E}$ & $\begin{array}{c}1 a_{1} \rightarrow e^{*}(41) \\
2 a_{1} \rightarrow e^{*}(42) \\
a_{2} \rightarrow e^{*}(10)\end{array}$ & 312 & 0.60 & $\lambda_{3}$ \\
\hline \multicolumn{5}{|c|}{$\mathrm{LaClPz}$} \\
\hline $1^{1} \mathrm{E}$ & $\begin{array}{c}3 a_{1} \rightarrow e^{*}(15) \\
a_{2} \rightarrow e^{*}(82) \\
2 a_{1} \rightarrow e^{*}(47)\end{array}$ & 510 & 0.15 & $\lambda_{1}$ \\
\hline $4^{1} \mathrm{E}$ & $\begin{aligned} 3 a_{1} & \rightarrow e^{*} \\
a_{2} & \rightarrow e^{*}\end{aligned}$ & 346 & 0.08 & $\lambda_{2}$ \\
\hline $6^{1} \mathrm{E}$ & $\begin{array}{c}1 a_{1} \rightarrow e^{*}(12) \\
2 a_{1} \rightarrow e^{*}(38) \\
3 a_{1} \rightarrow e^{*}(36) \\
a_{2} \rightarrow e^{*}(11)\end{array}$ & 311 & 0.62 & $\lambda_{3}$ \\
\hline \multicolumn{5}{|c|}{$\mathrm{LuClPz}$} \\
\hline $1^{1} \mathrm{E}$ & $\begin{array}{c}2 a_{1} \rightarrow e^{*}(16) \\
a_{2} \rightarrow e^{*}(82) \\
1 a_{1} \rightarrow e^{*}(56)\end{array}$ & 510 & 0.16 & $\lambda_{1}$ \\
\hline $4^{1} \mathrm{E}$ & $\begin{aligned} 2 a_{1} & \rightarrow e^{*} \\
a_{2} & \rightarrow e^{*}\end{aligned}$ & 332 & 0.12 & $\lambda_{2}$ \\
\hline $5^{1} \mathrm{E}$ & $\begin{array}{c}1 a_{1} \rightarrow e^{*}(39) \\
2 a_{1} \rightarrow e^{*}(45) \\
a_{2} \rightarrow e^{*}(11)\end{array}$ & 311 & 0.62 & $\lambda_{3}$ \\
\hline
\end{tabular}


Table 3. Cont.

\begin{tabular}{|c|c|c|c|c|}
\hline State & Composition (\%) & $\Lambda(\mathrm{nm})$ & $\mathbf{f}$ & \\
\hline \multicolumn{5}{|c|}{ YCITTDPz } \\
\hline $1^{1} \mathrm{E}$ & $\begin{array}{c}5 a_{1} \rightarrow 1 e^{*}(5) \\
3 a_{2} \rightarrow 1 e^{*}(91) \\
4 a_{1} \rightarrow 1 e^{*}\end{array}$ & 588 & 0.27 & $\lambda_{1}$ \\
\hline $5^{1} \mathrm{E}$ & $\begin{aligned} 5 a_{1} & \rightarrow 1 e^{*} \\
2 b_{1} & \rightarrow 1 e^{*}(10) \\
3 a_{1} & \rightarrow 1 e^{*} \\
4 a_{1} & \rightarrow 1 e^{*}\end{aligned}$ & 342 & 0.23 & $\lambda_{2}$ \\
\hline $6^{1} \mathrm{E}$ & $\begin{aligned} 5 a_{1} & \rightarrow 1 e^{*}(36) \\
3 a_{2} & \rightarrow 1 e^{*}(6) \\
3 a_{2} & \rightarrow 2 e^{*}\end{aligned}$ & 319 & 0.67 & $\lambda_{3}$ \\
\hline \multicolumn{5}{|c|}{ LaClTTDPz } \\
\hline $1^{1} \mathrm{E}$ & $\begin{array}{c}5 a_{1} \rightarrow 1 e^{*}(6) \\
3 a_{2} \rightarrow 1 e^{*}(91) \\
4 a_{1} \rightarrow 1 e^{*}(80)\end{array}$ & 582 & 0.27 & $\lambda_{1}$ \\
\hline $5^{1} \mathrm{E}$ & $\begin{aligned} 5 a_{1} & \rightarrow 1 e^{*}(10) \\
3 b_{1} & \rightarrow 1 e^{*}(10) \\
3 a_{1} & \rightarrow 1 e^{*}(21) \\
4 a_{1} & \rightarrow 1 e^{*}(7)\end{aligned}$ & 344 & 0.08 & \\
\hline $6^{1} \mathrm{E}$ & $\begin{aligned} 5 a_{1} & \rightarrow 1 e^{*} \\
3 a_{2} & \rightarrow 1 e^{*}(5) \\
3 a_{2} & \rightarrow 2 e^{*} \\
2 a_{1} & \rightarrow 1 e^{*}\end{aligned}$ & 329 & 0.48 & $\lambda_{2}$ \\
\hline $7^{1} \mathrm{E}$ & $\begin{array}{l}3 a_{1} \rightarrow 1 e^{*}(61) \\
5 a_{1} \rightarrow 1 e^{*}(14)\end{array}$ & 308 & 0.36 & $\lambda_{3}$ \\
\hline \multicolumn{5}{|c|}{ LuClTTDPz } \\
\hline $1^{1} \mathrm{E}$ & $\begin{array}{c}5 a_{1} \rightarrow 1 e^{*}(5) \\
3 a_{2} \rightarrow 1 e^{*}(91) \\
4 a_{1} \rightarrow 1 e^{*}\end{array}$ & 590 & 0.27 & $\lambda_{1}$ \\
\hline $5^{1} \mathrm{E}$ & $\begin{aligned} 5 a_{1} & \rightarrow 1 e^{*}(49) \\
3 b_{1} & \rightarrow 1 e^{*}(10) \\
3 a_{1} & \rightarrow 1 e^{*} \\
4 a_{1} & \rightarrow 1 e^{*}\end{aligned}$ & 342 & 0.26 & $\lambda_{2}$ \\
\hline $6^{1} \mathrm{E}$ & $\begin{aligned} 5 a_{1} & \rightarrow 1 e^{*} \\
3 a_{2} & \rightarrow 1 e^{*}(6) \\
3 a_{2} & \rightarrow 2 e^{*}\end{aligned}$ & 318 & 0.67 & $\lambda_{3}$ \\
\hline
\end{tabular}

\subsection{Molecular Orbitals}

The energy diagram of molecular orbitals for MClPz and MCITTDPz is shown in Figure 3. The HOMO energies are close in the series LaClPz-YClPz-LuClPz and LaClTTDPzYCITTDPz-LuClTTDPz, which allows us to conclude that the influence of a metal is insignificant. At the same time, the fusion of thiadiazole rings to the porphyrazine macrocycle leads to a decrease in the HOMO energy, which indicates an increase in the acceptor properties of the compound. In addition, the thiadiazole ring presence significantly reduces the HOMO-LUMO gap from approximately 2.6 to $2.3 \mathrm{eV}$. A similar situation was observed when considering the $\mathrm{Ca}$ (II) and $\mathrm{Zn}$ (II) complexes with porphyrazine and tetrakis(1,2,5thiadiazole)porphyrazine [17] and the HOMO-LUMO gap of magnesium(II) tetra(1,2,5chalcogenadiazolo)porphyrazines, [TXDPzMg] $(\mathrm{X}=\mathrm{O}, \mathrm{S}, \mathrm{Se}, \mathrm{Te})$ is close and varies from $\sim 2.0$ to $\sim 2.2 \mathrm{eV}$ [37]. 


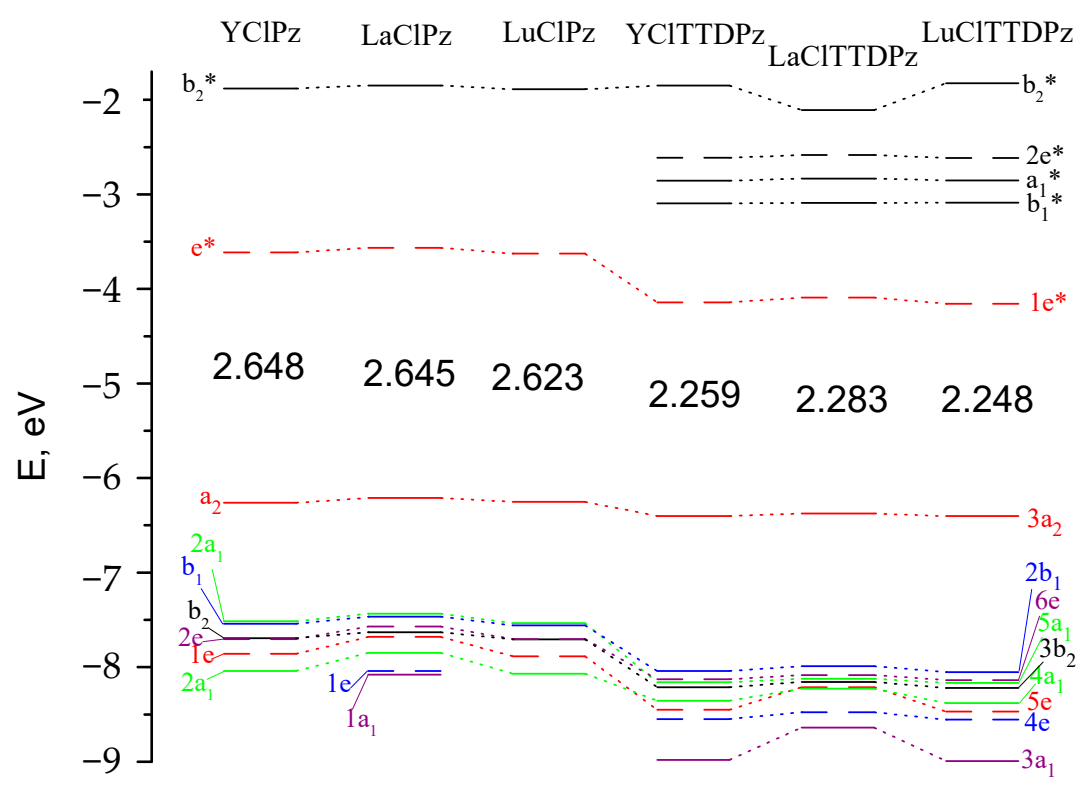

Figure 3. Molecular orbital (MO) level diagram for MClPz and MCITTDPz complexes. The values of highest occupied molecular orbital-lowest unoccupied molecular orbital (HOMO-LUMO) gaps are given in $\mathrm{eV}$.

The shapes of molecular orbitals (MOs) that participate in electronic transitions with large oscillator strengths are shown in Figures 4 and 5. Figures 4 and 5 show that LUMO and $\mathrm{HOMO}$ are linear combinations of $\pi$-bonding and $\pi$-antibonding molecular orbitals of the macrocycle, while HOMO- 1 and HOMO- 6 contain both atomic orbitals (AOs) of the macrocycle and $\mathrm{AOs}$ of metal and axial ligand $\mathrm{Cl}$. It should be noted that the shapes of HOMO and LUMO for all considered complexes are similar. However, HOMO exhibits a bonding character for the $\mathrm{C}_{\alpha}-\mathrm{C}_{\beta}$ bond in the case of MClPz and an antibonding character for MCITTDPz complexes. Differences in the molecular orbitals of the complexes MCIPz are observed in the compositions of the HOMO-1 and HOMO-6 MOs (Figure 4). Thus, in the $\mathrm{LaClPz}$ molecule, the electron density is shifted towards the $\mathrm{Cl}$ atom, while in $\mathrm{LuClPz}$ and $\mathrm{YClPz}$ the $\mathrm{Cl}$ atom has practically no electron density (HOMO-1). In MClTTDPz molecules, the main contribution to transitions to excited electronic states with the highest oscillator strength is made by the LUMO, HOMO, HOMO-2, HOMO-3, and HOMO-5 (HOMO-4 for LaClTTDPz) orbitals. The shapes of these orbitals are shown in Figure 5. A comparative analysis of the selected MOs reveals differences in the shape of 6e orbitals. In the case of LaClTTDPz, the electron density belongs to the macrocycle, while in the La and $Y$ complexes, the orbitals of the chlorine atom contribute. Of further note is the shape of the $4 \mathrm{a}_{1}$ orbitals, which are a linear combination of bonding and antibonding MOs of the macrocycle and metal. Thus, it can be observed that, in the LaCITTDPz molecule, it includes a bonding $\pi$-orbital at the $C_{\beta}-C_{\beta}$ bond, while these MOs of the LuCITTDPz and YCITTDPz molecules can be considered as completely antibonding. 
$\operatorname{LUMO}\left(e^{*}\right)$
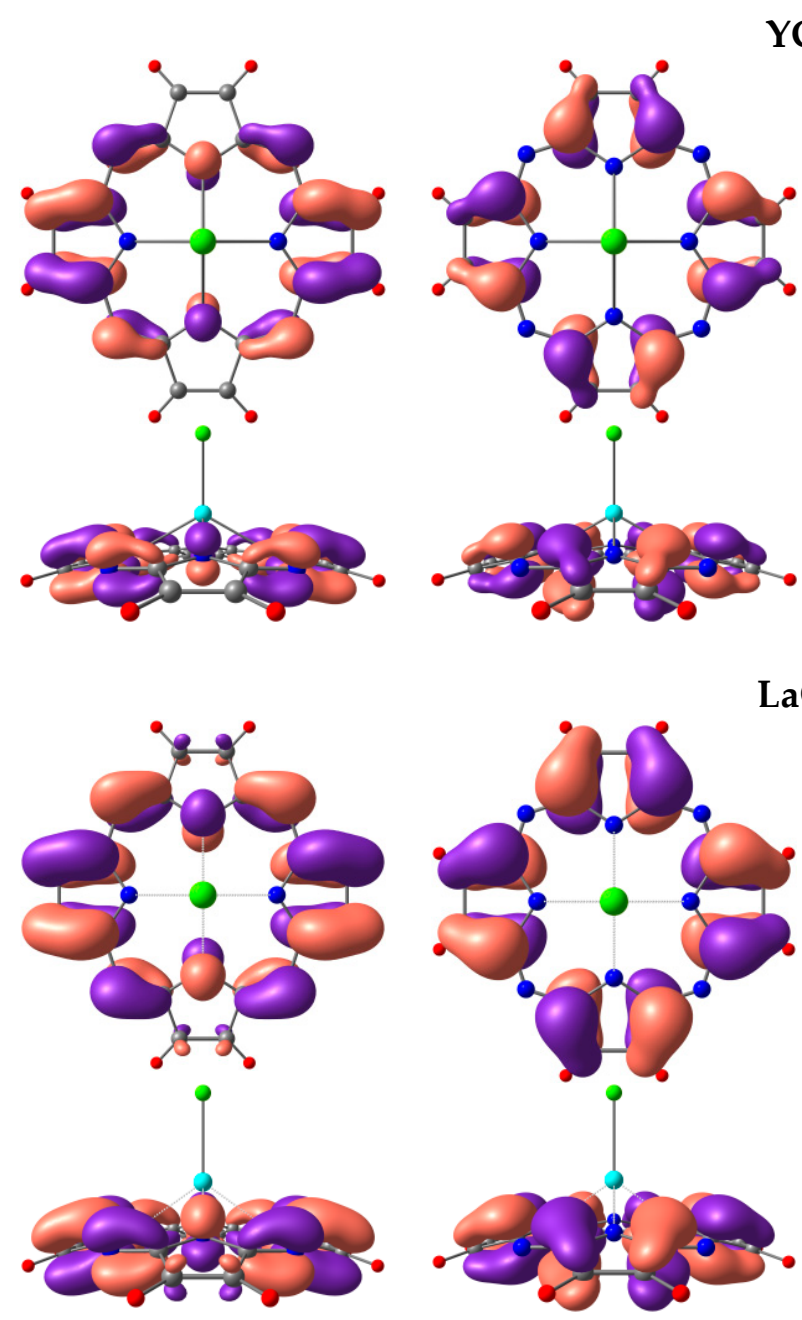
YClPz

HOMO-1( $3 a_{1}$ for La HOMO-6 ( $2 a_{1}$ for La and $2 a_{1}$ for $\left.\mathrm{Lu}, \mathrm{Y}\right)$ and $1 a_{1}$ for $\mathrm{Lu}, \mathrm{Y}$ )
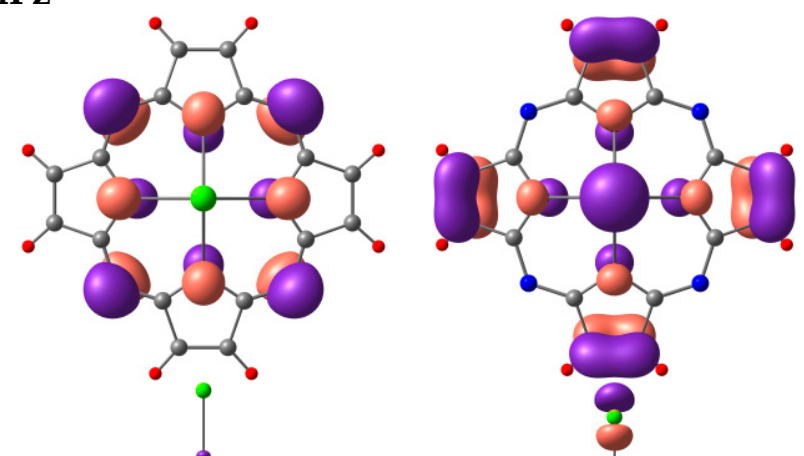

\section{$\mathrm{LaClPz}$}
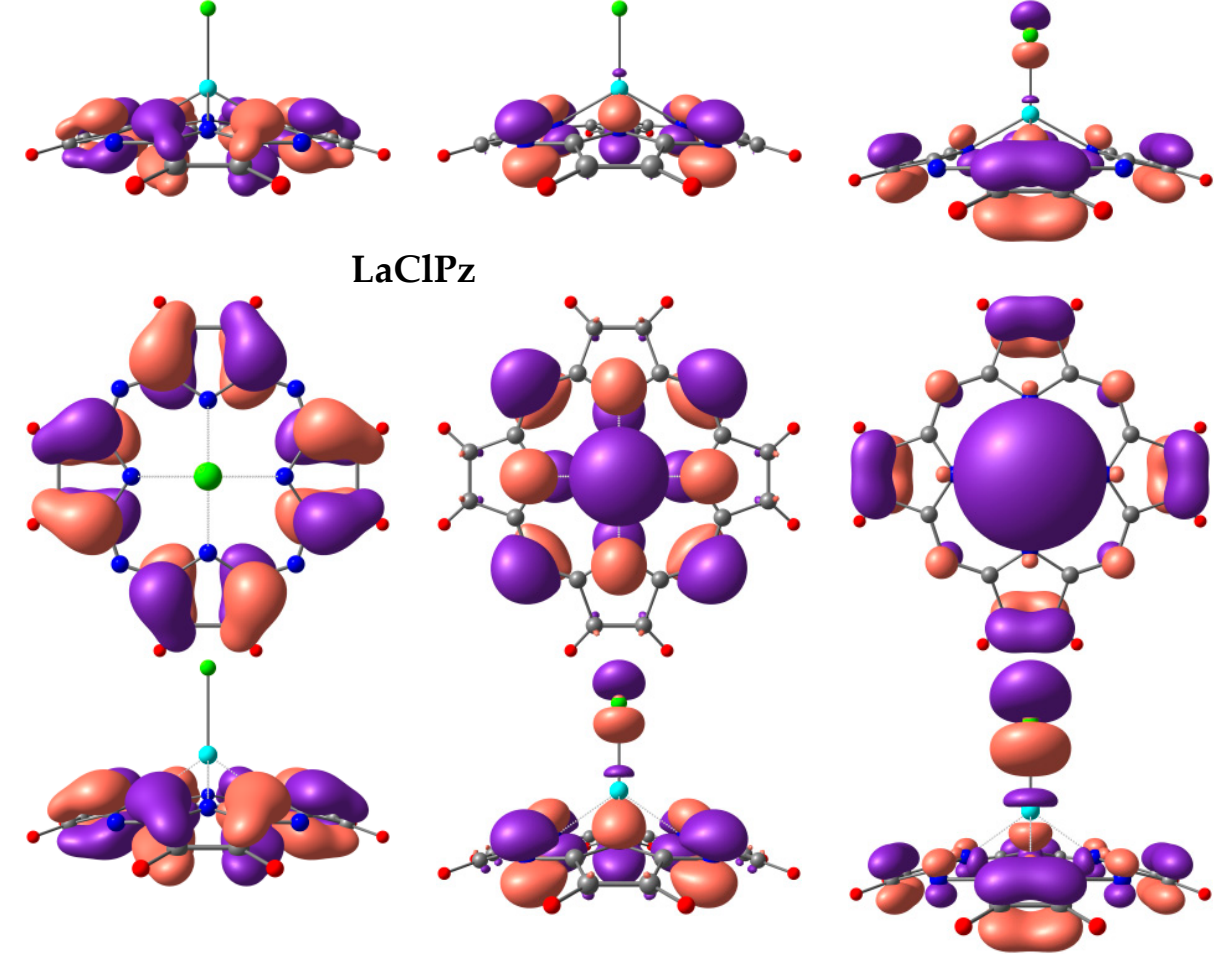

$\mathrm{LuClPz}$
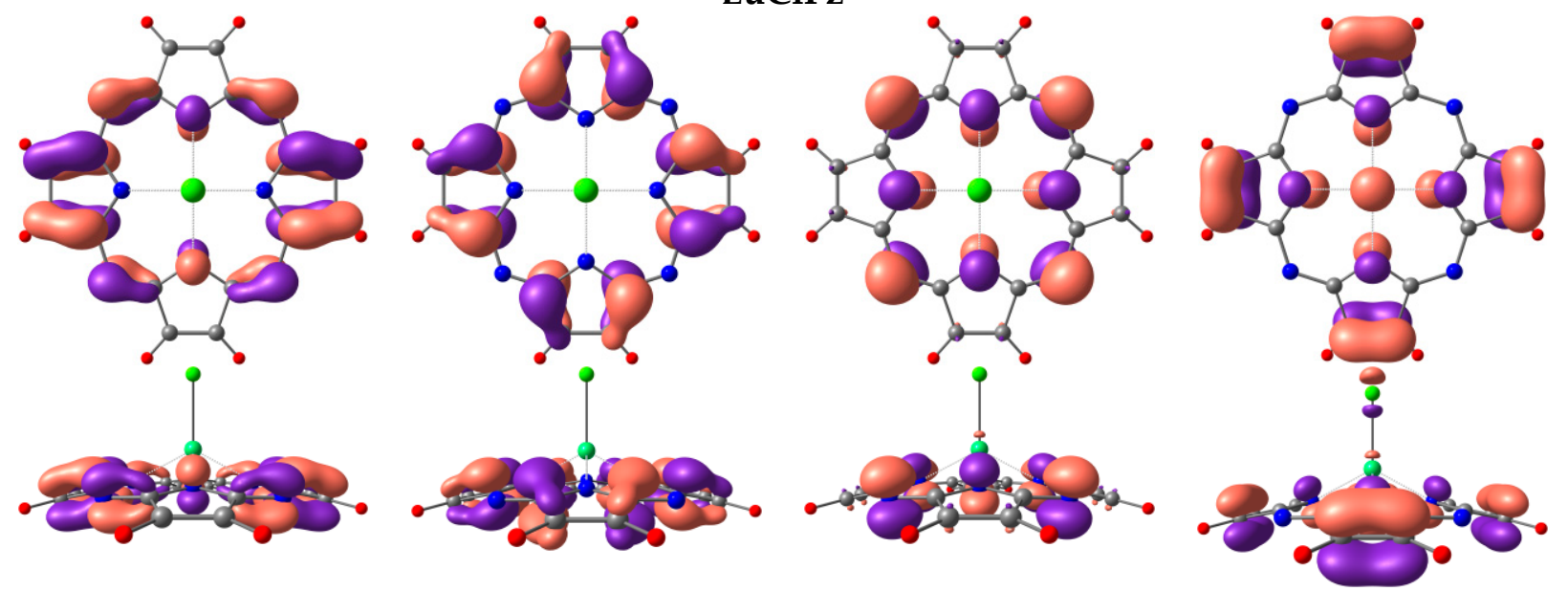

Figure 4. Influence of the metal $(\mathrm{Y}, \mathrm{La}, \mathrm{Lu})$ on the molecular orbitals of MClPz complexes. 
HOMO-5(HOMO-6 for La) $\left(4 a_{1}\right)$
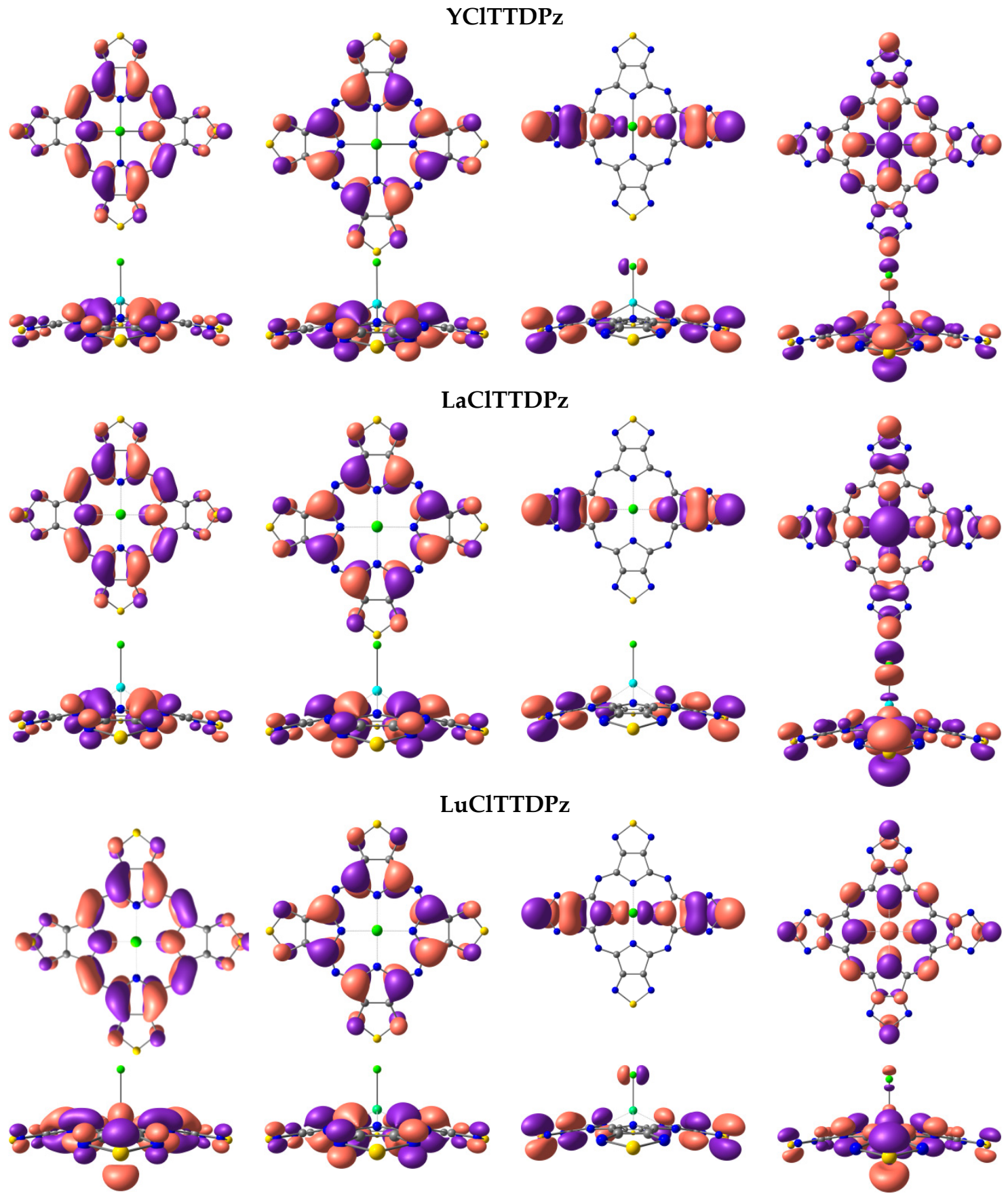

Figure 5. Influence of the metal $(\mathrm{Y}, \mathrm{La}, \mathrm{Lu})$ on the molecular orbitals of MClTTDPz complexes.

\subsection{Vibrational Spectra}

Recently, a description of the absorption bands of the vibrational spectrum of YCITTDPz and LuClTTDPz complexes was published in [20]. Detailed interpretation of IR-spectra for MCITTDPz and MCIPz is performed in the present work. The IR spectra were simulated on the basis of the normal mode frequencies and band intensities, which have been calculated by the DFT (B3LYP/pcseg-2) method in a harmonic approximation. Description of the main vibrations is presented in Table 4 (full list of the most active vibrations can be found in Supplementary Materials) and simulated spectra are shown in Figure 6. 
In the Y-La-Lu series a high-frequency band shift occurs both in MCITTDPz and in MClPz. The main differences between MClTTDPz and MClPz spectra occur in the positions and characters of the most intensive band, as well as the larger number of intense peaks in MClPz especially noticeable in high-frequency region. The most intensive peak is located in the $982 \mathrm{~cm}^{-1}$ region and corresponds predominantly to $C_{\alpha}-C_{\beta}$ stretching for $\mathrm{MClPz}$ complexes. In the case of MCITTDPz the strongest band is observed at $\sim 1290 \mathrm{~cm}^{-1}$ $\left(\omega_{87}-\omega_{88}\right)$ and mainly represented by stretching and bending in the macrocyclic fragment. Spectra of $\mathrm{MClPz}$ contain more intensive peaks as compared to MClTTDPz. The largest contribution to the $\omega_{85}-\omega_{86}$ bands in $\mathrm{MClPz}$ is $\mathrm{C}_{\beta}-\mathrm{C}_{\beta}$ stretching. The $\mathrm{N}_{\mathrm{m}}-\mathrm{C}_{\alpha}$ stretching vibrations contribute strongly to relatively weak bands $\omega_{82}-\omega_{83}$. In the case of the $\mathrm{LaClPz}$ $\omega_{76}$ band representing mainly in-plane bending/stretching, it possesses a higher intensity than the corresponding one in $\mathrm{LuClPz}$ and $\mathrm{YClPz}$. The out-of-plane deformations provide a major contribution to the medium band $\omega_{48}$. The $\mathrm{M}-\mathrm{Cl}$ stretching vibrations make a significant contribution to the weak bands in the low frequencies region for $\mathrm{MClPz}$ and for MCITTDPz too. MCITTDPz have similar IR-spectra in the 500-1600 $\mathrm{cm}^{-1}$ region where the influence of the metal is almost absent. In this region vibrations of the macrocyclic core are observed. The $\omega_{50}-\omega_{51}$ and $\omega_{80}-\omega_{81}$ bands in MCITTDPz spectra are composed by $\mathrm{N}_{\mathrm{p}}-\mathrm{C}_{\alpha}$ and $\mathrm{N}_{\mathrm{m}}-\mathrm{C}_{\alpha}$ stretching vibrations combined with in-plane deformations of the rings. Despite the noted significant covalent character of the bonding of the metal with the macrocycle, the stretching vibrations involving metal are detected only in the low frequencies region or have a low intensity. A performed description of calculated IR spectra shows that the most observed bands cannot be assigned to any single vibrational mode and are the result of the some vibrational modes superpositions.

Table 4. Assignment of the IR vibrations of the MCIPz and MCITTDPz complexes.

\begin{tabular}{|c|c|c|c|c|}
\hline Frequency, $\mathrm{cm}^{-1}$ & $\mathrm{I}_{\mathrm{rel}}, \%$ & Symmetry & Assignment $^{1}$ & Exp, $\mathrm{cm}^{-1}$ \\
\hline \multicolumn{5}{|l|}{ YClTTDPz } \\
\hline $1101.6\left(\omega_{80}-\omega_{81}\right)$ & 59 & E & $\begin{array}{c}\mathrm{r}\left(\mathrm{N}_{\mathrm{p}}-\mathrm{C}_{\alpha}\right)(24), \mathrm{r}\left(\mathrm{N}_{\mathrm{m}}-\mathrm{C}_{\alpha}\right)(28), \mathrm{r}\left(\mathrm{C}_{\alpha}-\mathrm{C}_{\beta}\right)(15), \mathrm{r}\left(\mathrm{C}_{\beta}-\mathrm{N}_{\mathrm{t}}\right)(9) \\
\varphi\left(\mathrm{C}_{\beta} \mathrm{C}_{\beta} \mathrm{N}_{\mathrm{t}}\right)(6), \varphi\left(\mathrm{C}_{\beta} \mathrm{N}_{\mathrm{t}} \mathrm{S}\right)(7)\end{array}$ & 1090 acac [20] \\
\hline $1280.0\left(\omega_{87}-\omega_{88}\right)$ & 100 & E & $\begin{array}{c}\mathrm{r}\left(\mathrm{N}_{\mathrm{p}}-\mathrm{C}_{\alpha}\right)(27), \mathrm{r}\left(\mathrm{C}_{\beta}-\mathrm{C}_{\beta}\right)(10), \mathrm{r}\left(\mathrm{C}_{\beta}-\mathrm{N}_{\mathrm{t}}\right)(10), \varphi\left(\mathrm{C}_{\alpha} \mathrm{N}_{\mathrm{p}} \mathrm{C}_{\alpha}\right)(6) \\
\varphi\left(\mathrm{N}_{\mathrm{p}} \mathrm{C}_{\alpha} \mathrm{N}_{\mathrm{m}}\right)(10), \varphi\left(\mathrm{N}_{\mathrm{m}} \mathrm{C}_{\alpha} \mathrm{C}_{\beta}\right)(9), \varphi\left(\mathrm{C}_{\alpha} \mathrm{C}_{\beta} \mathrm{N}_{\mathrm{t}}\right)(6)\end{array}$ & 1260 acac [20] \\
\hline \multicolumn{5}{|l|}{ LaClTTDPz } \\
\hline $1100.2\left(\omega_{80}-\omega_{81}\right)$ & 61 & $\mathrm{E}$ & $\begin{array}{c}\mathrm{r}\left(\mathrm{N}_{\mathrm{p}}-\mathrm{C}_{\alpha}\right)(28), \mathrm{r}\left(\mathrm{N}_{\mathrm{m}}-\mathrm{C}_{\alpha}\right)(27), \mathrm{r}\left(\mathrm{C}_{\alpha}-\mathrm{C}_{\beta}\right)(14), \mathrm{r}\left(\mathrm{C}_{\beta}-\mathrm{N}_{\mathrm{t}}\right)(8) \\
\varphi\left(\mathrm{C}_{\beta} \mathrm{C}_{\beta} \mathrm{N}_{\mathrm{t}}\right)(5), \varphi\left(\mathrm{C}_{\beta} \mathrm{N}_{\mathrm{t}} \mathrm{S}\right)(6)\end{array}$ & \\
\hline $1274.8\left(\omega_{87}-\omega_{88}\right)$ & 100 & $\mathrm{E}$ & $\begin{array}{c}\mathrm{r}\left(\mathrm{N}_{\mathrm{p}}-\mathrm{C}_{\alpha}\right)(29), \mathrm{r}\left(\mathrm{C}_{\beta}-\mathrm{C}_{\beta}\right)(8), \mathrm{r}\left(\mathrm{C}_{\beta}-\mathrm{N}_{\mathrm{t}}\right)(9), \varphi\left(\mathrm{C}_{\alpha} \mathrm{N}_{\mathrm{p}} \mathrm{C}_{\alpha}\right)(6) \\
\varphi\left(\mathrm{N}_{\mathrm{p}} \mathrm{C}_{\alpha} \mathrm{N}_{\mathrm{m}}\right)(10), \varphi\left(\mathrm{C}_{\alpha} \mathrm{N}_{\mathrm{m}} \mathrm{C}_{\alpha}\right)(5), \varphi\left(\mathrm{N}_{\mathrm{m}} \mathrm{C}_{\alpha} \mathrm{C}_{\beta}\right)(9) \\
\varphi\left(\mathrm{C}_{\alpha} \mathrm{C}_{\beta} \mathrm{N}_{\mathrm{t}}\right)(6)\end{array}$ & \\
\hline \multicolumn{5}{|c|}{ 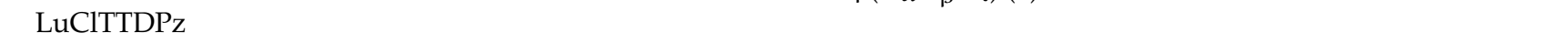 } \\
\hline $1102.1\left(\omega_{80}-\omega_{81}\right)$ & 59 & E & $\begin{array}{c}r\left(N_{p}-C_{\alpha}\right)(24), \\
, r\left(N_{m}-C_{\alpha}\right)(28), r\left(C_{\alpha}-C_{\beta}\right)(15), r\left(C_{\beta}-N_{t}\right)(9) \\
\varphi\left(C_{\beta} C_{\beta} N_{t}\right)(6), \varphi\left(C_{\beta} N_{t} S\right)(7)\end{array}$ & 1090 acac [20] \\
\hline $1281.5\left(\omega_{87}-\omega_{88}\right)$ & 100 & E & $\begin{array}{c}\mathrm{r}\left(\mathrm{N}_{\mathrm{p}}-\mathrm{C}_{\alpha}\right)(26), \mathrm{r}\left(\mathrm{C}_{\beta}-\mathrm{C}_{\beta}\right)(10), \mathrm{r}\left(\mathrm{C}_{\beta}-\mathrm{N}_{\mathrm{t}}\right)(10), \varphi\left(\mathrm{C}_{\alpha} \mathrm{N}_{\mathrm{p}} \mathrm{C}_{\alpha}\right)(6) \\
\varphi\left(\mathrm{N}_{\mathrm{p}} \mathrm{C}_{\alpha} \mathrm{N}_{\mathrm{m}}\right)(10), \varphi\left(\mathrm{N}_{\mathrm{m}} \mathrm{C}_{\alpha} \mathrm{C}_{\beta}\right)(9), \varphi\left(\mathrm{C}_{\alpha} \mathrm{C}_{\beta} \mathrm{N}_{\mathrm{t}}\right)(8)\end{array}$ & 1262 acac [20] \\
\hline \multicolumn{5}{|c|}{ 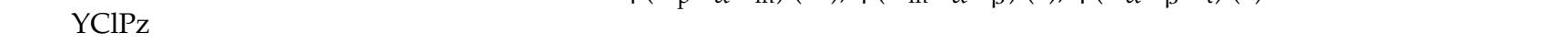 } \\
\hline $839.81\left(\omega_{48}\right)$ & 46 & $\mathrm{~A}_{1}$ & $\begin{array}{c}\mathrm{OPB}\left(\mathrm{C}_{\beta}-\mathrm{N}_{\mathrm{p}}-\mathrm{N}_{\mathrm{m}}-\mathrm{C}_{\alpha}\right)(35), \mathrm{OPB}\left(\mathrm{H}-\mathrm{C}_{\alpha}-\mathrm{C}_{\beta}-\mathrm{C}_{\beta}\right)(44) \\
\quad \theta\left(\mathrm{C}_{\alpha}-\mathrm{N}_{\mathrm{m}}-\mathrm{C}_{\alpha}-\mathrm{N}_{\mathrm{p}}\right)(5), \theta\left(\mathrm{N}_{\mathrm{m}}-\mathrm{C}_{\alpha}-\mathrm{C}_{\beta}-\mathrm{C}_{\beta}\right)\end{array}$ & \\
\hline $\begin{array}{l}982.30\left(\omega_{53}-\omega_{54}\right) \\
\mathrm{LaClPz}\end{array}$ & 100 & $\mathrm{E}$ & $r\left(N_{p}-Y\right)(5), r\left(N_{p}-C_{\alpha}\right)(14), r\left(C_{\alpha}-C_{\beta}\right)(53), r\left(C_{\alpha}-C_{\beta}\right)(5)$ & \\
\hline $838.13\left(\omega_{48}\right)$ & 44 & $\mathrm{~A}_{1}$ & $\begin{array}{c}\mathrm{OPB}\left(\mathrm{C}_{\beta}-\mathrm{N}_{\mathrm{p}}-\mathrm{N}_{\mathrm{m}}-\mathrm{C}_{\alpha}\right)(35), \mathrm{OPB}\left(\mathrm{H}-\mathrm{C}_{\alpha}-\mathrm{C}_{\beta}-\mathrm{C}_{\beta}\right)(44) \\
\quad \theta\left(\mathrm{C}_{\alpha}-\mathrm{N}_{\mathrm{m}}-\mathrm{C}_{\alpha}-\mathrm{N}_{\mathrm{p}}\right)(5), \theta\left(\mathrm{N}_{\mathrm{m}}-\mathrm{C}_{\alpha}-\mathrm{C}_{\beta}-\mathrm{C}_{\beta}\right)(11)\end{array}$ & \\
\hline $\begin{array}{l}975.65\left(\omega_{53}-\omega_{54}\right) \\
\mathrm{LuClPz}\end{array}$ & 100 & $\mathrm{E}$ & $\mathrm{r}\left(\mathrm{N}_{\mathrm{p}}-\mathrm{La}\right)(5), \mathrm{r}\left(\mathrm{N}_{\mathrm{p}}-\mathrm{C}_{\alpha}\right)(15), \mathrm{r}\left(\mathrm{N}_{\mathrm{m}}-\mathrm{C}_{\alpha}\right)(5), \mathrm{r}\left(\mathrm{C}_{\alpha}-\mathrm{C}_{\beta}\right)(56)$ & \\
\hline $839.62\left(\omega_{48}\right)$ & 46 & $\mathrm{~A}_{1}$ & $\begin{array}{c}\mathrm{OPB}\left(\mathrm{C}_{\beta}-\mathrm{N}_{\mathrm{p}}-\mathrm{N}_{\mathrm{m}}-\mathrm{C}_{\alpha}\right)(35), \mathrm{OPB}\left(\mathrm{H}-\mathrm{C}_{\alpha}-\mathrm{C}_{\beta}-\mathrm{C}_{\beta}\right)(45) \\
\quad\left(\mathrm{C}_{\alpha}-\mathrm{N}_{\mathrm{m}}-\mathrm{C}_{\alpha}-\mathrm{N}_{\mathrm{p}}\right)(5), \theta\left(\mathrm{N}_{\mathrm{m}}-\mathrm{C}_{\alpha}-\mathrm{C}_{\beta}-\mathrm{C}_{\beta}\right)(11)\end{array}$ & \\
\hline $983.45\left(\omega_{53}-\omega_{54}\right)$ & 100 & $\mathrm{E}$ & $\begin{array}{c}\mathrm{r}\left(\mathrm{N}_{\mathrm{p}}-\mathrm{Lu}\right)(5), \mathrm{r}\left(\mathrm{N}_{\mathrm{p}}-\mathrm{C}_{\alpha}\right)(7), \mathrm{r}\left(\mathrm{N}_{\mathrm{p}}-\mathrm{C}_{\alpha}\right)(7), \mathrm{r}\left(\mathrm{C}_{\alpha}-\mathrm{C}_{\beta}\right)(26) \\
\mathrm{r}\left(\mathrm{C}_{\alpha}-\mathrm{C}_{\beta}\right)(27)\end{array}$ & \\
\hline
\end{tabular}

${ }^{1}$ Coordinates are listed provided that their contributions (shown in parentheses) are greater than $\sim 5 \%$. Assignment of vibrational modes based on potential energy distribution. The following designations of the coordinates are used: $\mathrm{r}$-stretching of the bond; $\varphi$ - bending, a change in the angle; $\mathrm{OPB}$ - out-of-plane bending; $\theta$ - a change in the dihedral angle. 


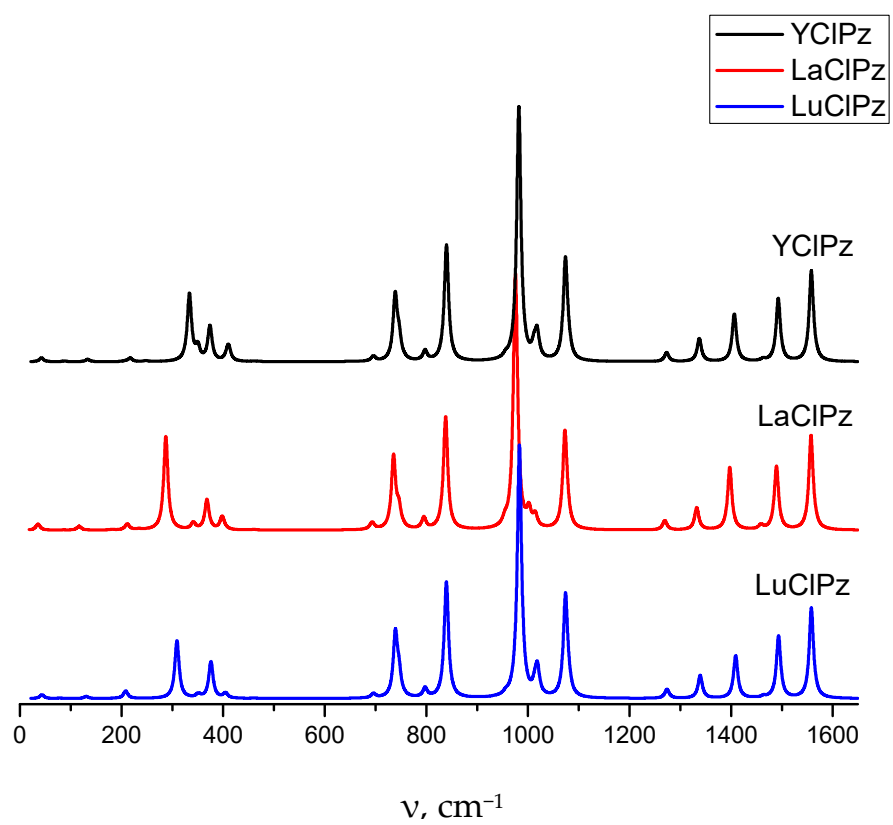

(a)

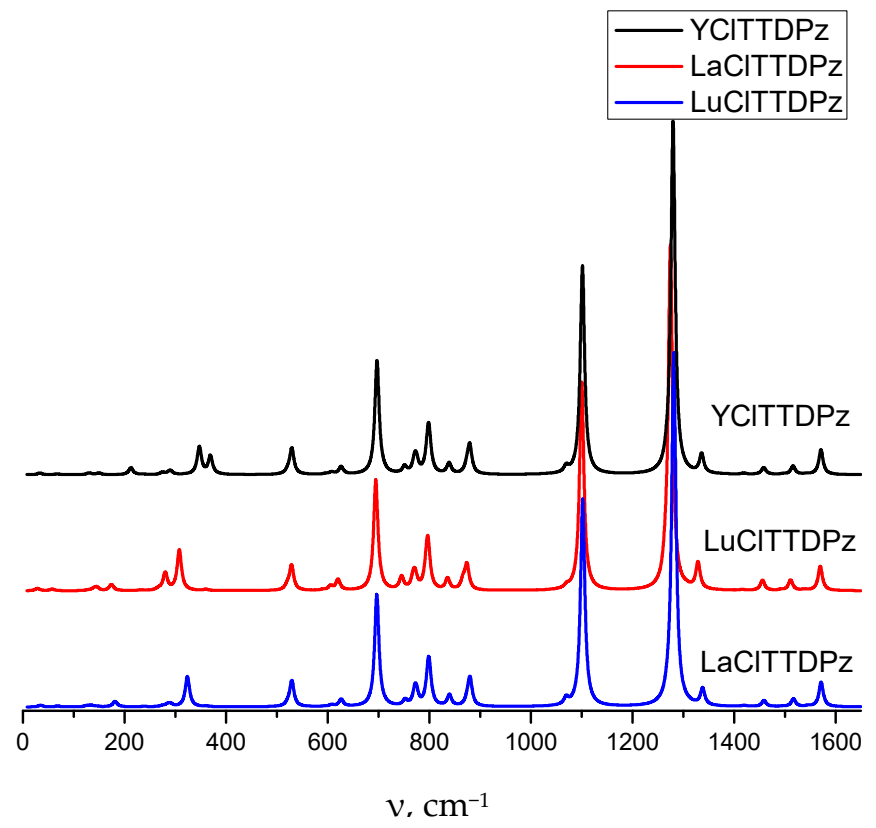

(b)

Figure 6. Simulated vibrational spectra of the MClPz (a) and $\mathrm{MClTTDPz}(\mathbf{b})$ complexes.

\section{Materials and Methods \\ Computational Details}

The DFT-based investigation of MClPz and MClTTDPz included geometry optimizations and computations of the harmonic vibrations followed by TDDFT calculations of the electronic absorption spectrum. The number of the calculated excited states was 30 . The calculations were performed using the B3LYP functional with the use of pcseg-2 basis set [38] taken from the EMSL BSE library [39,40] for describing the electron shells of C, N, $\mathrm{S}, \mathrm{Cl}$ and $\mathrm{H}$ atoms. For describing the 28 core electron shells and 11 valence electrons of the yttrium atom pseudopotential combined with corresponding basis set cc-pVTZ-PP [41] were used. In case of the lanthanum atom 46 core electron shells were described by pseu- 
dopotential [42] and 11 valence electrons were described by Def2-TZVPP [42] basis sets. For the description of 11 valence electrons of the $\mathrm{Lu}$ atom triple- $\zeta$ valence basis sets [43] were used and 60 core shells were described by an effective core pseudopotential [44] developed by the Stuttgart group. The Firefly QC [45] package, which is partially based on the GAMESS(US) [46] source code was used in all the calculations.

Optimized Cartesian coordinates of MPz and MTTDPz are available from Supplementary Materials.

Description of the vibrational modes is carried out based on the analysis of the distribution of the potential energy of normal vibrations by natural vibrational coordinates. This analysis was performed using the VibModule program [47].

The quantum theory of atoms in molecules (QTAIM) analysis [48] was performed using the AIMAll [49] software package. Topological parameters of $\rho(r)$ in bond critical points and charges on atoms are collected in Supplementary Materials.

The molecular models and orbitals demonstrated in the paper were visualized by means of the Chemcraft program [50].

\section{Conclusions}

The influence of the nature of the metal $(\mathrm{Y}, \mathrm{La}, \mathrm{Lu})$ and the ligand (either porphyrazine or thiadiazole-annelated porphyrazine) on the geometry, electronic structure and electronic and vibrational absorption spectra of the macroheterocyclic complex was studied by DFT calculations at the B3LYP/pcseg-2 level.

It has been shown that the ligand cavity can adjust itself to the size of the central atom in a way that results in doming distortion of the ligand without changing the structure of the periphery of the macrocycle. It has been found that the electron density distribution in the coordination cavity of metal complexes of porphyrazine and tetra $(1,2,5-$ thiadiazole)porphyrazine slightly depends on the nature of the ligand and metal.

The value of the lanthanide contraction $\Delta \mathrm{r}_{\mathrm{Ln}}$ in the studied complexes has been determined, which turned out to be close to $\Delta \mathrm{r}_{\mathrm{Ln}}$ in the series of lanthanide halogenides with three monovalent ligands and in the series of lanthanide compounds with three bidentate ligands.

The incorporation of a substituent can enhance the effect of the metal on the spectral properties of the complexes. The electronic spectra of investigated complexes can be described by the model of Gouterman. It has been shown that in the calculated IR spectra the most intense bands cannot be assigned to any single vibrational mode and are the result of the superposition of vibrational modes.

Supplementary Materials: Cartesian coordinates of YCIPz optimized B3LYP/pcseg-2 level of theory, Cartesian coordinates of LaClPz optimized B3LYP/pcseg-2 level of theory, Cartesian coordinates of LuClPz optimized B3LYP/pcseg-2 level of theory, Cartesian coordinates of YCITTDPz optimized B3LYP/pcseg-2 level of theory, Cartesian coordinates of LaClTTDPz optimized B3LYP/pcseg-2 level of theory, Cartesian coordinates of LuClTTDPz optimized B3LYP/pcseg-2 level of theory, Table S1: Calculated composition of the lowest excited states and corresponding oscillator strengths for $\mathrm{MClPz}$ and MCITTDPz complexes, Table S2: Assignment of the IR vibrations of the MCIPz and MCITTDPz complexes, Table S3: Bond lengths and topological parameters of $\rho(\mathrm{r})$ in bond critical points of the MClPz, Table S4: Bond lengths and topological parameters of $\rho(r)$ in bond critical points of the MCITTDPz, Table S5: Charge on atoms in MCIPz and MCITTDPz.

Author Contributions: Conceptualization, P.A.S.; Methodology, Y.A.Z.; Investigation, I.A.K. and A.V.E.; Resources, Y.A.Z.; Data Curation, I.V.R.; Writing—original draft preparation, I.V.R. All authors have read and agreed to the published version of the manuscript.

Funding: This work is supported by the Russian Science Foundation (grant № 19-73-00256).

Data Availability Statement: The data presented in this study are available in supplementary material.

Conflicts of Interest: The authors declare no conflict of interest. 


\section{References}

1. Sorokin, A.B. Recent progress on exploring $\mu$-oxo bridged binuclear porphyrinoid complexes in catalysis and material science. Coord. Chem. Rev. 2019, 389, 141-160. [CrossRef]

2. Yu, Z.; Hagfeldt, A.; Sun, L. The application of transition metal complexes in hole-transporting layers for perovskite solar cells: Recent progress and future perspectives. Coord. Chem. Rev. 2020, 406, 213143. [CrossRef]

3. Almeida-Marrero, V.; Van De Winckel, E.; Anaya-Plaza, E.; Torres, T.; De La Escosura, A. Porphyrinoid biohybrid materials as an emerging toolbox for biomedical light management. Chem. Soc. Rev. 2018, 47, 7369-7400. [CrossRef] [PubMed]

4. Wöhrle, D.; Schnurpfeil, G.; Makarov, S.G.; Kazarin, A.; Suvorova, O.N. Practical Applications of Phthalocyanines-From Dyes and Pigments to Materials for Optical, Electronic and Photo-electronic Devices. Macroheterocycles 2012, 5, 191-202. [CrossRef]

5. Lukyanets, E.A.; Nemykin, V.N. The key role of peripheral substituents in the chemistry of phthalocyanines and their analogs. J. Porphyr. Phthalocyanines 2010, 14, 1-40. [CrossRef]

6. Longevial, J.; Clément, S.; Wytko, J.A.; Ruppert, R.; Weiss, J.; Richeter, S. Peripherally Metalated Porphyrins with Applications in Catalysis, Molecular Electronics and Biomedicine. Chem. Eur. J. 2018, 24, 15442-15460. [CrossRef]

7. Bettini, S.; Valli, L.; Giancane, G. Applications of Photoinduced Phenomena in Supramolecularly Arranged Phthalocyanine Derivatives: A Perspective. Molecules 2020, 25, 3742. [CrossRef]

8. Donzello, M.P.; Ercolani, C.; Novakova, V.; Zimcik, P.; Stuzhin, P.A. Tetrapyrazinoporphyrazines and their metal derivatives. Part I: Synthesis and basic structural information. Coord. Chem. Rev. 2016, 309, 107-179. [CrossRef]

9. Novakova, V.; Donzello, M.P.; Ercolani, C.; Zimcik, P.; Stuzhin, P.A. Tetrapyrazinoporphyrazines and their metal derivatives. Part II: Electronic structure, electrochemical, spectral, photophysical and other application related properties. Coord. Chem. Rev. 2018, 361, 1-73. [CrossRef]

10. Donzello, M.P.; Ercolani, C.; Stuzhin, P.A. Novel families of phthalocyanine-like macrocycles-Porphyrazines with annulated strongly electron-withdrawing 1,2,5-thia/selenodiazole rings. Coord. Chem. Rev. 2006, 250, 1530-1561. [CrossRef]

11. Suzuki, Y.; Fujimori, M.; Yoshikawa, H.; Awaga, K. Packing motifs and magneto-structural correlations in crystal structures of metallo-tetrakis(1,2,5-thiadiazole)porphyrazine series, MTTDPz (M=H 2, Fe, Co, Ni, Cu, Zn). Chem. Eur. J. 2004, 10, $5158-5164$. [CrossRef] [PubMed]

12. Koifman, O.I.; Ageeva, T.A.; Beletskaya, I.P.; Averin, A.D.; Yakushev, A.A.; Tomilova, L.G.; Dubinina, T.V.; Tsivadze, A.Y.; Gorbunova, Y.G.; Stuzhin, P.A.; et al. Macroheterocyclic Compounds-A Key Building Block in New Functional Materials and Molecular Devices. Macroheterocycles 2020. [CrossRef]

13. Weiss, R.; Fischer, J. Lanthanide Phthalocyanine Complexes. In The Porphyrin Handbook: Phthalocyanines: Spectroscopic and Electrochemical Characterization; Elsevier Inc.: Cambridge, MA, USA, 2003; Volume 16, pp. 171-246. ISBN 9780123932266.

14. Bouvet, M.; Gaudillat, P.; Suisse, J.-M. Lanthanide macrocyclic complexes: From molecules to materials and from materials to devices. J. Porphyr. Phthalocyanines 2013, 17, 628-635. [CrossRef]

15. Stuzhin, P.A.; Ivanova, S.S.; Hamdoush, M.; Kirakosyan, G.A.; Kiselev, A.; Popov, A.; Sliznev, V.; Ercolani, C. Tetrakis(1,2,5thiadiazolo)porphyrazines. 9. Synthesis and spectral and theoretical studies of the lithium(i) complex and its unusual behaviour in aprotic solvents in the presence of acids. Dalton Trans. 2019, 48, 14049-14061. [CrossRef]

16. Stuzhin, P.A.; Bauer, E.M.; Ercolani, C. Tetrakis(thiadiazole)porphyrazines. 1. Syntheses and Properties of Tetrakis(thiadiazole)porphyrazine and Its Magnesium and Copper Derivatives. Inorg. Chem. 1998, 37, 1533-1539. [CrossRef]

17. Otlyotov, A.A.; Ryzhov, I.V.; Kuzmin, I.A.; Zhabanov, Y.A.; Mikhailov, M.S.; Stuzhin, P.A. DFT Study of Molecular and Electronic Structure of $\mathrm{Ca}(\mathrm{II})$ and $\mathrm{Zn}(\mathrm{II})$ Complexes with Porphyrazine and tetrakis(1,2,5-thiadiazole)porphyrazine. Int. J. Mol. Sci. 2020, 21, 2923. [CrossRef]

18. Donzello, M.P.; Agostinetto, R.; Ivanova, S.S.; Fujimori, M.; Suzuki, Y.; Yoshikawa, H.; Shen, J.; Awaga, K.; Ercolani, C.; Kadish, K.M.; et al. Tetrakis(thiadiazole)porphyrazines. 4. Direct template synthesis, structure, general physicochemical behavior, and redox properties of Al III, GaIII, and InIII complexes. Inorg. Chem. 2005, 44, 8539-8551. [CrossRef]

19. Bauer, E.M.; Cardarilli, D.; Ercolani, C.; Stuzhin, P.A.; Russo, U. Tetrakis(thiadiazole)porphyrazines. 2. Metal complexes with $\mathrm{Mn}(\mathrm{II}), \mathrm{Fe}(\mathrm{II}), \mathrm{Co}(\mathrm{II}), \mathrm{Ni}(\mathrm{II})$, and Zn(II). Inorg. Chem. 1999, 38, 6114-6120. [CrossRef]

20. Tarakanova, E.N.; Hamdoush, M.; Eroshin, A.V.; Ryzhov, I.V.; Zhabanov, Y.A.; Stuzhin, P.A. Tetra(1,2,5-thiadiazolo)porphyrazines. 10. Synthesis, spectral characterization and DFT study of complexes with yttrium(III) and lutetium(III). Polyhedron 2021, 193, 114877. [CrossRef]

21. Khelevina, O.G.; Voinov, A.A. Synthesis and kinetic stability of dysprosium(III), europium(III), and neodymium(III) complexes with tetraazaporphine in acetic acid solutions. Russ. J. Gen. Chem. 2000, 70, 778-783.

22. Khelevina, O.G.; Voinov, A.A. Kinetic stability of the dysprosium(III) complex with tetraazaporphine in water-acetic acid and methanol-acetic acid mixtures. Russ. J. Coord. Chem. Khimiya 1999, 25, 445-449.

23. Zhabanov, Y.A.; Sliznev, V.V.; Ryzhov, I.V.; Stuzhin, P.A. Peculiarities of electronic structure and chemical bonding in iron and cobalt metal complexes of porphyrazine and tetra(1,2,5-thiadiazole)porphyrazine. J. Porphyr. Phthalocyanines 2020, 24, 1146-1154. [CrossRef]

24. Bader, R.F.W.; Slee, T.S.; Cremer, D.; Kraka, E. Description of conjugation and hyperconjugation in terms of electron distributions. J. Am. Chem. Soc. 1983, 105, 5061-5068. [CrossRef]

25. Shannon, R.D. Revised effective ionic radii and systematic studies of interatomic distances in halides and chalcogenides. Acta Crystallogr. Sect. A 1976, 32, 751-767. [CrossRef] 
26. Zhabanov, Y.A.; Giricheva, N.I.; Zakharov, A.V.; Islyaikin, M.K. Distinctive features of the structure of hemihexaphyrazine complexes with Y, La, and Lu according to quantum chemical data. J. Mol. Struct. 2017, 1132. [CrossRef]

27. Giricheva, N.I.; Zakharov, A.V.; Shlykov, S.A.; Girichev, G.V. Molecular structure of GdCl3. Nuclear dynamics of the trichlorides of Gd, Tm, and Lu. J. Chem. Soc. Dalton Trans. 2000, 19, 3401-3403. [CrossRef]

28. Zakharov, A.V.; Vogt, N.; Shlykov, S.A.; Giricheva, N.I.; Galanin, I.E.; Girichev, G.V.; Vogt, J. The molecular structures of LaCl3 and $\mathrm{LaBr} 3$ reinvestigated by gas-phase electron diffraction. J. Mol. Struct. 2004, 707, 147-152. [CrossRef]

29. Shlykov, S.A.; Giricheva, N.I.; Lapykina, E.A.; Girichev, G.V.; Oberhammer, H. The molecular structure of TbI3, DyI3, HoI3 and ErI3 as determined by synchronous gas-phase electron diffraction and mass spectrometric experiment assisted by quantum chemical calculations. J. Mol. Struct. 2010, 978, 170-177. [CrossRef]

30. Giricheva, N.I.; Shlykov, S.A.; Lapykina, E.A.; Oberhammer, H.; Girichev, G.V. The molecular structure of PrI3 and GdI3 as determined by synchronous gas-phase electron diffraction and mass spectrometric experiment assisted by quantum chemical calculations. Struct. Chem. 2011, 22, 385-392. [CrossRef]

31. Ischenko, A.A.; Girichev, G.V.; Tarasov, Y.I. Difraktciya Elektronov: Struktura i Dinamika Svobodnykh Molekul i Kondensirovannogo Sostoyaniya Veshestva; Fizmatlit: Moscow, Russia, 2012.

32. Giricheva, N.I.; Belova, N.V.; Shlykov, S.A.; Girichev, G.V.; Vogt, N.; Tverdova, N.V.; Vogt, J. Molecular structure of tris(dipivaloylmethanato)lanthanum(III) studied by gas electron diffraction. J. Mol. Struct. 2002, 605, 171-176. [CrossRef]

33. Belova, N.V.; Girichev, G.V.; Hinchley, S.L.; Kuzmina, N.P.; Rankin, D.W.H.; Zaitzeva, I.G. Molecular structure of tris(dipivaloylmethanato)lutetium(iii) studied by gas electron diffraction and ab initio and DFT calculations. Dalton Trans. 2004, 1715-1718. [CrossRef] [PubMed]

34. Gouterman, M. Spectra of porphyrins. J. Mol. Spectrosc. 1961, 6, 138-163. [CrossRef]

35. Gouterman, M.; Wagnière, G.H.; Snyder, L.C. Spectra of porphyrins. Part II. Four orbital model. J. Mol. Spectrosc. 1963, 11, 108-127. [CrossRef]

36. Weiss, C.; Kobayashi, H.; Gouterman, M. Spectra of porphyrins. Part III. Self-consistent molecular orbital calculations of porphyrin and related ring systems. J. Mol. Spectrosc. 1965, 16, 415-450. [CrossRef]

37. Zhabanov, Y.A.; Tverdova, N.V.; Giricheva, N.I.; Girichev, G.V.; Stuzhin, P.A. DFT Study of molecular and electronic structure of magnesium (II) tetra(1,2,5-chalcogenadiazolo) porphyrazines, [TXDPzMg] (X= O, S, Se, Te). J. Porphyr. Phthalocyanines 2017, 21, 439-452. [CrossRef]

38. Jensen, F. Unifying general and segmented contracted basis sets. Segmented polarization consistent basis sets. J. Chem. Theory Comput. 2014, 10, 1074-1085. [CrossRef]

39. Pritchard, B.P.; Altarawy, D.; Didier, B.; Gibson, T.D.; Windus, T.L. New Basis Set Exchange: An Open, Up-to-Date Resource for the Molecular Sciences Community. J. Chem. Inf. Model. 2019. [CrossRef]

40. Schuchardt, K.L.; Didier, B.T.; Elsethagen, T.; Sun, L.; Gurumoorthi, V.; Chase, J.; Li, J.; Windus, T.L. Basis set exchange: A community database for computational sciences. J. Chem. Inf. Model. 2007, 47, 1045-1052. [CrossRef]

41. Peterson, K.A.; Figgen, D.; Dolg, M.; Stoll, H. Energy-consistent relativistic pseudopotentials and correlation consistent basis sets for the 4d elements Y-Pd. J. Chem. Phys. 2007, 126, 124101. [CrossRef]

42. Weigend, F.; Ahlrichs, R. Balanced basis sets of split valence, triple zeta valence and quadruple zeta valence quality for $\mathrm{H}$ to Rn: Design and assessment of accuracy. Phys. Chem. Chem. Phys. Des. Assess. Accuracy 2005, 7, 3297-3305. [CrossRef]

43. Weigand, A.; Cao, X.; Yang, J.; Dolg, M. Quasirelativistic f-in-core pseudopotentials and core-polarization potentials for trivalent actinides and lanthanides: Molecular test for trifluorides. Theor. Chem. Acc. 2009, 126, 117-127. [CrossRef]

44. Dolg, M.; Stoll, H.; Savin, A.; Preuss, H. Energy-adjusted pseudopotentials for the rare earth elements. Theor. Chim. Acta 1989, 75, 173-194. [CrossRef]

45. Granovsky, A.A. Firefly Version 8. Available online: http://classic.chem.msu.su/gran/firefly/index.html (accessed on 28 December 2020).

46. Schmidt, M.W.; Baldridge, K.K.; Boatz, J.A.; Elbert, S.T.; Gordon, M.S.; Jensen, J.H.; Koseki, S.; Matsunaga, N.; Nguyen, K.A.; Su, S.; et al. General atomic and molecular electronic structure system. J. Comput. Chem. 1993, 14, 1347-1363. [CrossRef]

47. Vishnevskiy, Y.V.; Zhabanov, Y.A. New implementation of the first-order perturbation theory for calculation of interatomic vibrational amplitudes and corrections in gas electron diffraction. J. Phys. Conf. Ser. 2015, 633, 12076. [CrossRef]

48. Bader, R.F.W. Atoms in Molecules: A Quantum Theory; Oxford University Press: Oxford, UK; Clarendon Press: Oxford, UK, 1990; ISBN 9780198558651.

49. Some References Related to AIMAll. Available online: http:/ / aim.tkgristmill.com/references.html (accessed on 13 March 2020).

50. Zhurko, G.A.; Zhurko, D.A. ChemCraft Version 1.6 (Build 312); Version 1.6 (Build 312) Ed. Available online: http://www. chemcraftprog.com/index.html (accessed on 28 December 2020). 